\title{
Aortic Valve Replacement in the Wolff-Parkinson-White Syndrome
}

\author{
D. R. RICHMOND AND D. R. SMITH \\ From the Cardiac Investigation Unit, The General Infirmary, Leeds
}

Although the Wolff-Parkinson-White syndrome was first documented in 1930 (Wolff, Parkinson, and White, 1930), there have been only occasional reports of heart operations being performed in patients with this syndrome. Martins de Oliveira et al. (1958) described total correction of the tetralogy of Fallot in a 7-year-old child with the WolffParkinson-White syndrome who died 18 hours after operation. In this patient, the presence of the syndrome was not considered to have affected or determined the outcome. More recently, Green, Bartley, and Schiebler (1965) described successful closure of a ventricular septal defect in an 18-year-old man with an intermittent Wolff-Parkinson-White syndrome, and again it was not considered to have influenced events.

Our purpose in describing a patient with this syndrome who had aortic valve replacement is to show that arrhythmias may give rise to considerable difficulties in management under some circumstances.

\section{Case History}

The patient was a 24 -year-old Greek. He had rheumatic fever at age 10 years, and heart disease was diagnosed at 12 years of age. At 16 years he was in hospital for four months following tonsillectomy, because of a persistent "tachycardia".

His main complaints were of angina of effort and dyspnoea on exertion, with orthopnoea and nocturnal dyspnoea for 12 months, and of intermittent palpitations at rest and on effort for 8 years.

Examination. He was a well-built young man. The arterial pulse was regular and collapsing; all pulses were palpable. The blood pressure was $140 / 0 \mathrm{~mm}$. Hg. The jugular venous pressure was normal; there was no evidence of congestive heart failure. There was a heaving left ventricular impulse and a systolic ejection murmur in the second right intercostal space conducted to the carotid arteries, with a loud blowing early diastolic murmur at the left sternal edge. There was no clinical evidence of mitral valve disease.
Investigations. $\mathrm{Hb} 13.5 \mathrm{~g} .(91 \%)$; white blood cells 8400 and $10,400 / \mathrm{cu}$. mm. on two occasions; erythrocyte sedimentation rate 19 and $5 \mathrm{~mm}$./hr. on two occasions.

Chest $x$-ray and screening showed left ventricular enlargement, widening and unfolding of the aorta with recoil expansion and vigorous pulsation. No calcification of the aortic valve was observed.

Electrocardiogram showed sinus rhythm and severe left ventricular hypertrophy with intermittent WolffParkinson-White syndrome (Fig. 1). The QRS deflections were those of Type $B$ anomaly of conduction (Massie and Walsh, 1960).

Operation. This was performed by Mr. D. A. Watson in May 1965. A Melrose pump and disc oxygenator were used with coronary perfusion. The aortic valve cusps were found to be grossly shrunken and were removed. An aortic Starr-Edwards ball valve prosthesis was inserted and perfusion was discontinued.

Post-operative course. Immediately after the operation the cardiac rhythm varied between sinus rhythm with partial left bundle-branch block and Wolff-Parkinson-White conduction.

At 10.30 a.m. on the second post-operative day the patient was in stable Wolff-Parkinson-White rhythm (Fig. 2a). His general condition was good and intermittent positive pressure ventilation was discontinued. Tubocurarine chloride had been withheld for the preceding 6 hours but the patient failed to breathe spontaneously. For this reason neostigmine $2 \mathrm{mg}$. and atropine $0.6 \mathrm{mg}$. were given intravenously over a period of 5 minutes. Within seconds of receiving the full dose a supraventricular tachycardia started at a rate of 190 a minute (Fig. 2b), and the patient rapidly developed pulmonary oedema. Eyeball compression and carotid sinus stimulation slowed the rate only transiently, but neostigmine $2 \mathrm{mg}$. intravenously in 4 divided doses at 3-minute intervals terminated the episode, and the heart rate slowed to 130 a minute. The cardiac rhythm was then sinus with left bundle-branch block (Fig. 2c), and the manner of slowing suggested that the tachy582 


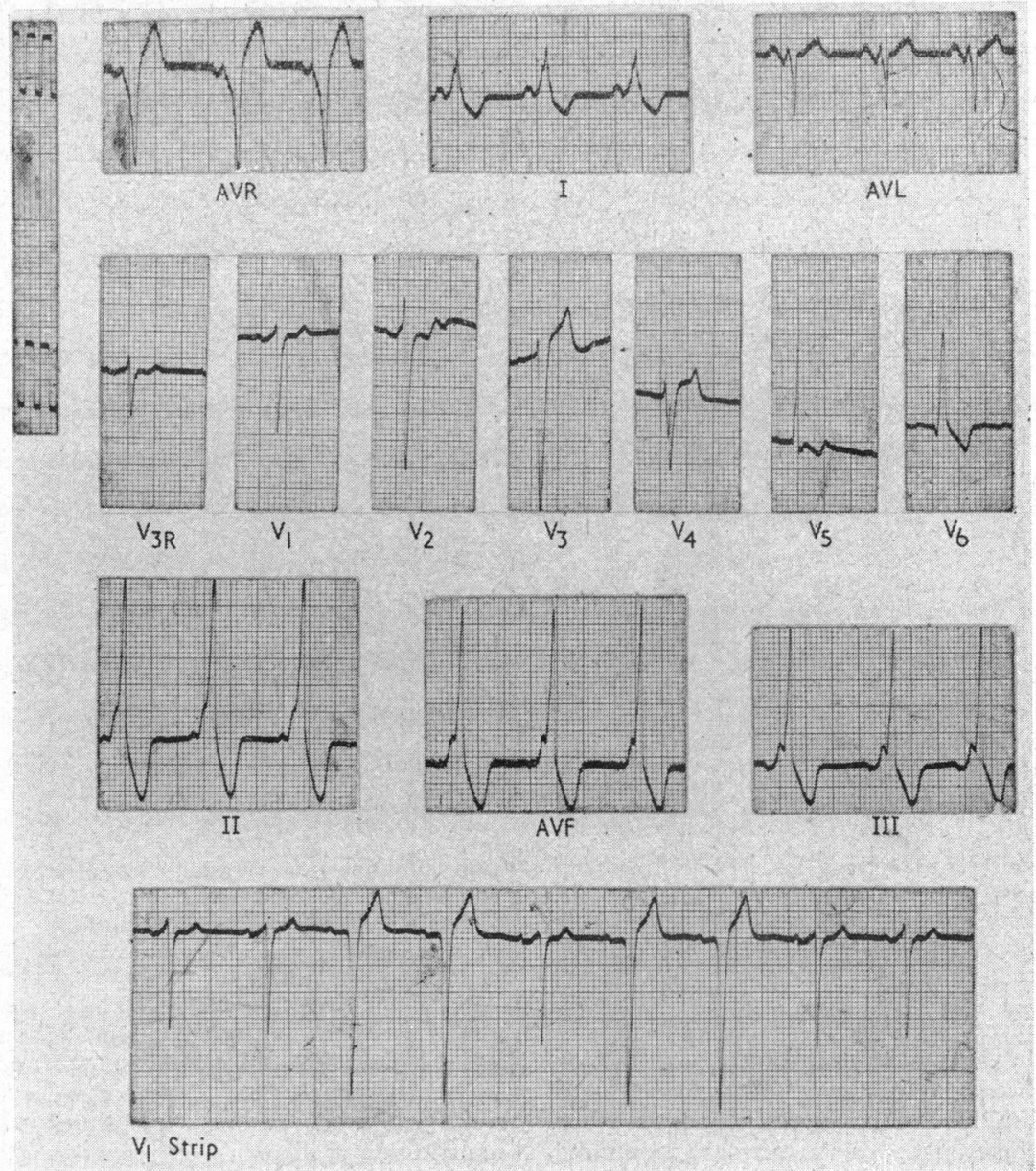

Fig. 1.-Pre-operative electrocardiogram showing sinus rhythm, left ventricular hypertrophy, and intermittent type B Wolff-Parkinson-White conduction. Praecordial leads recorded at half standardization.

down the "normal" pathway. The patient quickly improved and remained well for the following 72 hours. Digoxin $0.25 \mathrm{mg}$. twice a day, which was started on the first post-operative day, was continued.

Early on the sixth post-operative day at 4.30 a.m. a further supraventricular tachycardia developed with a heart rate of 200 a minute. The episode was terminated by a combination of neostigmine $1.5 \mathrm{mg}$. intravenously, carotid sinus stimulation, and corneal compression. This arrhythmia was similar to the previous one, shown in Fig. $2 b$ and 2 c, and again the manner of slowing suggested that, as in the first episode, the tachycardia was associated with conduction down the normal pathway. Without further treatment being given, the rhythm later changed to a stable Wolff-Parkinson-White rhythm with a rate of 130 a minute (Fig. 3). Neostigmine $15 \mathrm{mg}$. four-hourly by mouth was started as prophylaxis against further tachycardia; digoxin $0.25 \mathrm{mg}$. twice a day was continued.

On the evening of the same day the patient developed a fresh episode of tachycardia with a heart rate of 200 a minute. There was a dominantly negative deflection in the QRS complex in lead III (Fig. 4a). Neostigmine $0.75 \mathrm{mg}$. intravenously resulted in a slowing of the rate and the appearance of $P$ waves suggesting that this was a supraventricular tachycardia (Fig. 4b). Similar results followed eyeball compression. As the effect of the neostigmine diminished, the supraventricular tachycardia returned with acceleration of the ventricular rate from 120 to 200 a minute (Fig. 4c). Neostigmine was given in a further two doses of $0.75 \mathrm{mg}$. intravenously. On these occasions there was only very transient slowing of the ventricular rate with increasingly frequent appearance of Wolff-Parkinson-White complexes on the electrocardiogram, until a tachycardia (rate 200 a minute) with complexes of Wolff-Parkinson-White conduction ensued (Fig. 4d). As the effect of the neostigmine diminished, a tachycardia with normally conducted ventricular complexes recurred. On giving a further $0.75 \mathrm{mg}$. neostigmine intravenously the tachycardia with Wolff-Parkin- 
son-White complexes recurred. At this stage neostigmine and digoxin were discontinued.

It was decided to begin treatment with quinidine. An initial dose of quinidine $150 \mathrm{mg}$. intravenously was given, with electrocardiograph and blood pressure monitored. There was immediate slowing of the ventricular rate and return to sinus rhythm with left bundle-branch block, though intermittent Wolff-Parkinson-White complexes still occurred (Fig. 4e). A total of $1.4 \mathrm{~g}$. of quinidine was given over the first 12 hours $(0.3 \mathrm{~g}$. intravenously and $1 \cdot 1 \mathrm{~g}$. orally), and then a maintenance dose of $0.3 \mathrm{~g}$. six-hourly was begun. Brief episodes of tachycardia continued to occur but these were abolished by the reinstitution of digoxin $0.25 \mathrm{mg}$. twice a day.

At 5 and 10 weeks after the operation the electrocardiogram showed stable sinus rhythm with partial left bundle-branch block (Fig. 5). He returned to Greece taking quinidine and digoxin, together with maintenance

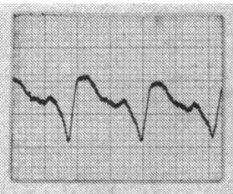

AVR

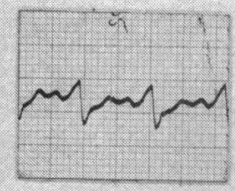

I

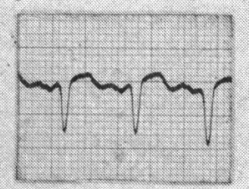

AVL

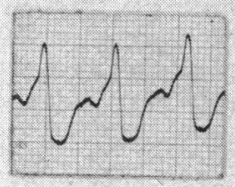

II

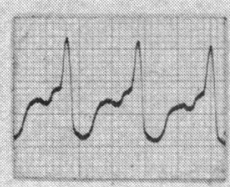

AVF

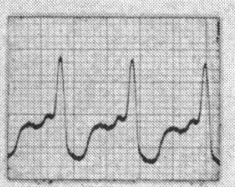

III

FIG. 3.-Electrocardiogram recorded on sixth day after operation, showing stable Wolff-Parkinson-White rhythm. 

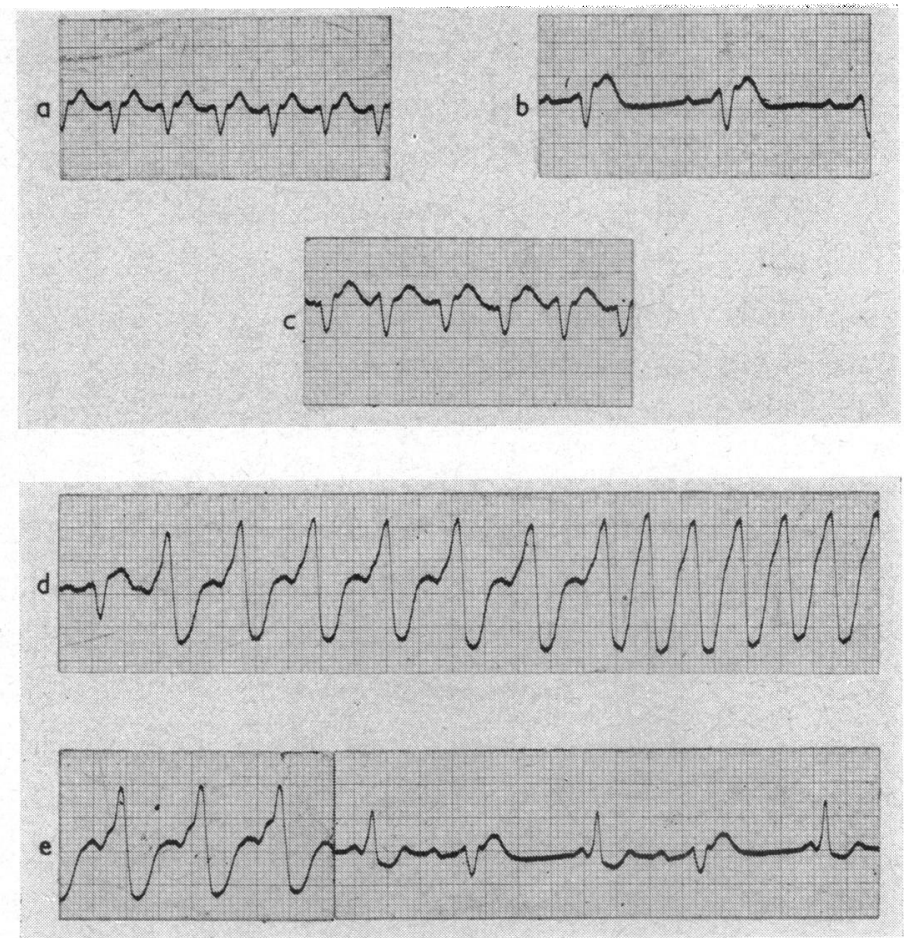

FIG. 4.-Electrocardiograms (lead III only) recorded on sixth day after operation. (a) Appearance of supraventricular tachycardia. (b) After $0.75 \mathrm{mg}$. neostigmine intravenously showing appearance of $P$ waves. (c) Recurrence of supraventricular tachycardia as effect of neostigmine diminishes. (d) Appearance of Wolff-Parkinson-White conduction after further $0.75 \mathrm{mg}$. neostigmine intravenously. (e) Effect of quinidine, $150 \mathrm{mg}$. given intravenously.

anticoagulant therapy, 10 weeks after the operation. A report from his local physician one year after operation stated that his general condition and exercise tolerance were greatly improved, but he continued to have brief paroxysms of tachycardia that could be terminated by eyeball compression.

\section{Discussion}

The pre-operative electrocardiogram satisfies the criteria for the diagnosis of the Wolff-ParkinsonWhite syndrome, showing complexes with a P-R interval of less than 0.12 sec., and a QRS of abnormal configuration, with a heavily slurred initial component or delta wave, prolonged to $0 \cdot 11-0 \cdot 14$ sec.

There was no evidence in the post-operative period of electrolyte imbalance, acid/base disturbance, or arterial hypoxia. Nevertheless, severe frequent arrhythmias occurred giving rise to considerable anxiety in management. This experience is in contrast with that of other authors (Martins de Oliveira et al., 1958; Green et al., 1965). We suggest that in patients with a history of tachycardia, open-heart surgery may precipitate alarming arrhythmias, and in these patients the presence of the Wolff-Parkinson-White syndrome constitutes an additional hazard.

This case is unusual in that supraventricular tachycardias with both normally and anomalously conducted QRS complexes were seen in the same patient. The first episodes of supraventricular tachycardia were of the normally conducted variety and responded to neostigmine (Rosenbaum, 1949).

In the last attack of supraventricular tachycardia, cholinergic stimulation did not prevent (and may possibly have induced) conduction down the anomalous pathway. Quinidine is said to decrease conduction in the anomalous pathways without favouring the emergence of normally conducted tachycardia (Langendorf, Lev, and Pick, 1952), and proved effective in this case.

\section{Summary}

The case is described of a patient who had an aortic valve replacement and was known to have an intermittent Wolff-Parkinson-White syndrome before operation, with a history of tachycardia. The 


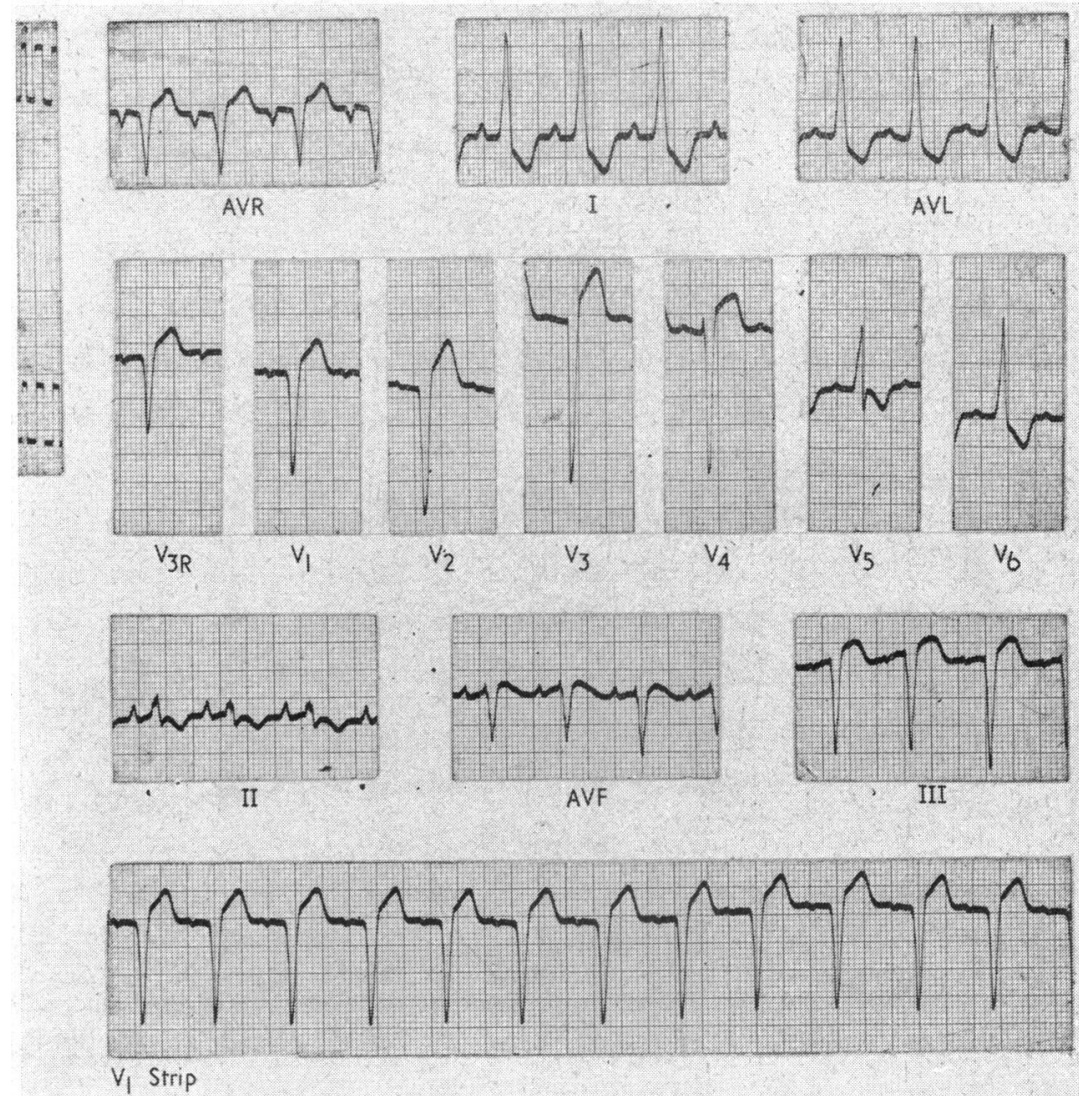

FIG. 5.-Electrocardiogram recorded 10 weeks after operation showing sinus rhythm and partial left bundlebranch block.

post-operative course is given in detail, with special reference to the occurrence of arrhythmias and their management. In contrast to the experience of other authors, it is suggested that the presence of the Wolff-Parkinson-White syndrome constitutes an additional hazard in open-heart surgery.

The unusual occurrence of supraventricular tachycardia with both normal and anomalous conduction in the same patient is noted.

We would like to thank Dr. J. R. H. Towers and Mr. D. A. Watson (under whose care the patient was admitted) for permission to publish this report, and Mrs. A. Hood for invaluable secretarial assistance.

\section{References}

Green, J. R., Bartley, T. D., and Schiebler, G. L. (1965). The Wolff-Parkinson-White syndrome and ventricular septal defect. A case report of successful surgery in an 18-year-old man. Dis. Chest, 47, 659.
Langendorf, R., Lev, M., and Pick, A. (1952). Auricular fibrillation with anomalous A-V excitation (WolffParkinson-White syndrome) imitating ventricular paroxysmal tachycardia. A case report with clinical and autopsy findings and critical review of the literature. Acta cardiol. (Brux.), 7, 241.

Martins de Oliveira, J., Mendelsohn, D., Nogueira, C., and Zimmerman, H. A. (1958). Wolff-Parkinson-White syndrome and tetralogy of Fallot. Report of a case. Amer. F. Cardiol., 2, 111.

Massie, E., and Walsh, T. (1960). Clinical Vectorcardiography and Electrocardiography. Year Book Publishers, Chicago.

Rosenbaum, F. F. (1949). The nature of paroxysmal tachycardia in anomalous atrioventricular excitation. Amer. Heart F., 37, 668.

Wolff, L., Parkinson, J., and White, P. D. (1930). Bundlebranch block with short P-R interval in healthy young people prone to paroxysmal tachycardia. Amer. Heart f., 5, 685 . 